\title{
Kajian Kinetika Adsorpsi Metilen Biru Menggunakan Adsorben Sabut Kelapa
}

\author{
Anselmus Boy Baunsele ${ }^{1}$; Hildegardis Missa² \\ ${ }^{1}$ Program Studi Pendidikan Kimia, FKIP, Universitas Katolik WIdya Mandira, Kupang, NTT \\ ${ }^{2}$ Program Studi Pendidikan Biologi, FKIP, Universitas Katolik Widya Mandira, Kupang, NTT \\ E-mail: boybaunsele@gmail.com
}

\begin{abstract}
Abstrak
Methylene blue is a dye that is widely used in various industries, but has a negative impact on the environment. The aim of this research is to reduce the impact of methylene blue on the environment. Coconut coir waste taken from the street vendors in Kupang City then made into an adsorbent for methylene blue adsorption. The results showed that the adsorption of methylene blue occurred optimally at $\mathrm{pH} 7$ for 75 minutes of adsorption with the adsorption percentage of $99.14 \%$. The results of the adsorption reaction kinetics analysis showed that the adsorption of methylene blue using coconut husk adsorbent followed the second-order pseudo reaction kinetics model with an adsorption constant rate of $0.01 \mathrm{~g} \mathrm{mg}^{-1}$ minute $^{-1}$
\end{abstract}

Kata kunci: methylene blue, adsorbent, kinetics reaction

\begin{abstract}
Abstrak
Metilen biru merupakan zat warna yang digunakan secara luas dalam berbagai industri namun memiliki dampak negatif terhadap lingkungan. Tujuan penelitian ini adalah untuk mengurangi dampak pencemaran metilen biru pada lingkungan air. Sabut kelapa yang diambil dari pedagang kaki lima di Kota Kupang dijadikan adsorben untuk adsorpsi metilen biru. Hasil penelitian menunjukkan bahwa adsorpsi metilen biru terjadi secara optimal pada pH 7 selama 75 menit adsorpsi dengan persentase adsorpsi sebesar 99,14\%. Hasil analisis kinetika reaksi adsorpsi menunjukkan bahwa adsorpsi metilen biru menggunakan adsorben sabut kelapa mengikuti model kinetika reaksi pseudo orde dua dengan laju konstanta adsorpsi sebesar 0,01 $\mathrm{gram} \mathrm{mg}^{-1} \mathrm{menit}^{-1}$.
\end{abstract}

Kata kunci: metilen biru, adsorben, kinetika reaksi

PENDAHULUAN

DOI: http://dx.doi.org/10.12962/j25493736.v5i2.7791
Indonesia akhir-akhir ini menjadi negara yang memiliki perkembangan cukup pesat dalam semua bidang. Salah satu aspek 
yang cukup tinggi perkembangannya adalah bidang industri tekstil. Perkembangan tersebut dipengaruhi oleh tingginya animo masyarakat terhadap keberagaman busana yang semakin variatif. Peningkatan tersebut berbanding lurus dengan adanya kerusakan lingkungan akibat limbah industri tekstil yang semakin menjamur. Pencemaran yang terjadi khususnya pada lingkungan air oleh limbah industri secara umum adalah logam berat dan zat warna. Terdapat banyak zat warna yang sering digunakan untuk keperluan pewarnaan tekstil dengan berbagai sifat kimia yang bervariasi diantaranya rodamin $\mathrm{B}$, metilen biru, metilen violet, tartrazi, sunset yellow dan allura red. Metilen biru merupakan salah satu zat warna dasar dengan struktur senyawa kimia aromatik heterosiklik. Pewarna kationik biasanya digunakan pada awalnya untuk mewarnai sutra, kulit, plastik, kertas, dan dalam pembuatan cat dan tinta ukiran [1]. Sumber lain metilen biru dapat berasal dari industri kertas dan kosmetik. Kehadiran zat warna sangat mempengaruhi lingkungan karena efek toksiknya yang tinggi, dapat menyebabkan alergi dan iritasi kulit, serta dapat menyebabkan perubahan gen dan bersifat karsinogenik [2]. Selain efek tersebut, mekanisme pencemaran lain yaitu jika suatu area perairan tercemar metilen biru maka akan terjadi penghambatan terhadap penetrasi sinar matahari yang menyebabkan menurunnya tingkatan fotosintesis tumbuhan air dan mengganggu ekosistem air karena dapat menyebabkan kurangnya kandungan oksigen terlarut. Paparan akut metilen biru bagi manusia dapat menyebabkan peningkatan detak jantung, muntah-muntah, dan sianosis pada manusia [3].

Dampak negatif metilen biru dapat dicegah atau kurangi dengan berbagai metode diantaranya secara elektrokimia yang memanfaatkan elektroda kombinasi polivinil klorida dan karbon (C-PVC)[4], metode fotokatalitik untuk mendegradasi metilen biru memanfaatkan katalis $\mathrm{TiO}_{2}$ [5][6]. Sedangkan metode lain yang cukup efektif adalah metode adsorpsi. Adsorpsi metilen biru dapat dilakukan menggunakan berbagai jenis adsorben diantaranya kitosan dan kitin [7], cangkang telur [8], limbah daun teh [9], kulit pisang [10], dan selulosa alang-alang [11].

Adsorpsi merupakan salah satu metode yang murah dan efektif dalam mengurangi dampak negatif lingkungan akibat pencemaran oleh zat warna maupun logam berat. Banyak bahan alam yang digunakan untuk mengadsorspi zat warna maupun bahan pencemar lain contohnya adsorpsi senyawa fenol dari karbon aktif batok kelapa [12], adsorpsi 2-klorofenol dan 2, 4, 6-triklorofenol menggunakan sabut kelapa [13], adsorpsi zat warna menggunakan limbah bahan pertanian [14][15], adsorpsi logam berat $\mathrm{Pb}$ menggunakan kaolin [16], pemanfaatan 
pektin dari kulit jeruk untuk adsorpsi logam berat kromium [17] dan adsorpsi tembaga menggunakan limbah pertanian [18]. Kelimpahan bahan alam menjadi salah satu alasan pemanfaatan sabut kelapa untuk adsorpsi metilen biru. Sabut kelapa telah dikembangkan untuk keperluan indistri yaitu pemanfaatan sabut kelapa sebagai biokomposit [19], sebagai bahan tambahan pembuatan semen [20][21], selain itu sabut kelapa juga dapat dimanfaatkan untuk adsorpsi pencemar diair diantaranya [22][23].

\section{METODOLOGI PENELITIAN}

\subsection{Preparasi Adsorben Sabut Kelapa}

Sabut Kelapa yang akan dijadikan sebagai adsorben diambil dari limbah sabut kelapa yang ada di kota Kupang. Limbah tersebut diperoleh dari pedagang kaki lima yang berjualan kelapa muda ataupun es kelapa muda. Sabut kelapa yang diambil kemudian dibersihkan dan dipisahkan antara serat kasarnya dengan kulit buah kelapanya. Serat kasar yang diperoleh selanjutnya ditumbuk atau dihaluskan dan kemudian diayak menggunakan ayakan berukuran 80 mesh. Serbuk sabut kelapa yang telah halus tersebut kemudian dicuci hingga bersih untuk menghilangkan pengotornya. Residu yang dihasilkan dikeringkan dengan dianginanginkan hingga kering. Setelah kering maka adsorben sabut kelapa siap untuk digunakan.
2.2 Pembuatan Larutan Stok Metilen Biru (MB) 100ppm

Larutan stok MB 100 ppm dibuat dengan cara menimbang sebanyak $100 \mathrm{mg}$ padatan metilen biru kemudian dilarutkan. Proses pelarutan dilakukan dengan menuangkan sedikit demi sedikit aquades hingga padatannya larut. Jika sudah larut maka larutan dipindahkan kedalam wadah labu ukur bervolume 1 L kemudian ditambahkan aquades hingga volumenya tepat 1 L. Larutan kemudian dikocok hingga benarbenar homogen. Selanjutnya larutan MB 100 ppm siap untuk digunakan.

\subsection{Penentuan Panjang Gelombang Maksimum}

Larutan MB 5 ppm $100 \mathrm{~mL}$ dibuat dengan mengambil sebanyak $5 \mathrm{~mL}$ larutan MB 100 ppm kemudian dimasukkan kedalam labu ukur $100 \mathrm{~mL}$ dan ditambahkan air hingga mencapai tanda batas. Campuran tersebut kemudian dikocok hingga homogen. Larutan MB 5 ppm kemudian diambil dan diukur absorbansinya menggunakan Spektrofotometer UV-Vis dengan panjang gelombang 200-800 nm.

\subsection{Pembuatan Kurva Kalibrasi}

Kurva kalibrasi MB diperoleh dengan mempersiapkan larutan MB yang diencerkan dari larutan stok MB 100 ppm dengan konsentrasi MB masing-masing yaitu 0, 1, 2, 3, 4, dan 5 ppm. Larutan yang telah disiapkan 
tersebut kemudian diukur absorbansinya dengan menggunakan panjang gelombang serapan maksimum yang telah diperoleh pada langkah sebelumnya. Data absorbansi versus konsentrasi digunakan untuk membuat kurva standar. Berdasarkan kurva yang diperoleh, persamaan garis lurus dapat ditentukan dan kemudian dipakai untuk menentukan kapasitasi adsorpsi maksimum pada variasi waktu kontak maupun $\mathrm{pH}$ larutan MB.

\subsection{Pengukuran Adsorpsi pH Maksimum}

Pengukuran adsorpsi maksimum pada variasi $\mathrm{pH}$ dilakukan dengan menyiapkan larutan MB dengan konsentrasi 10 ppm sebanyak $20 \mathrm{~mL}$. Sebanyak 11 wadah penampung disiapkan kemudian ke dalam wadah-wadah tersebut dimasukkan masingmasing larutan MB 10 ppm 20 mL. Wadah yang telah terisi larutan $\mathrm{MB}$ tersebut kemudian diatur $\mathrm{pH}$ larutannya 1 hingga dan ditambahkan masing-masing 0,1 gram adsorben sabut kelapa, selanjutnya dikocok dan didiamkan selama 60 menit. Setelah semua larutan siap maka dapat dilakukan penyaringan untuk memisahkan residu adsorben dan filtrat. Filtrat yang merupakan adsorbat kemudian diukur absorbansinya untuk mengetahui besarnya kapasitas adsorpsi MB oleh adsorben sabut kelapa, yang kemudian dijadikan $\mathrm{pH}$ optimum.
2.6 Pengukuran Adsorpsi MB dengan Variasi Waktu Kontak

Penentuan waktu kontak dilakukan dengan mengambil sebanyak masing-masing 20 mL larutan MB 10 ppm dan dimasukkan ke dalam 8 wadah yang berbeda. Setelah diisi dengan larutan MB kemudian dimasukkan sabut kelapa sebanyak 0,1 gram untuk tiap wadah. Tingkat keasaman larutan MB diatur menggunakan $\mathrm{pH}$ optimum. Wadah yang telah berisi adsorben dan larutan MB selanjutnya diukur absorbansinya dengan variasi waktu kontak selama 5, 10, 20, 40, 50, 75, 90 dan 120 menit. Selanjutnya diperoleh kapasitas adsorpsi pada masing-masing waktu kontak antara adsorben dan laruan MB. Banyaknya MB yang teradsorpsi dihitung dengan Persamaan 1.

$$
\operatorname{Serapan}(\%)=\frac{C o-C e}{C o} \times 100 \%
$$

Dengan, Co merupakan konsentrasi sebelum teradsorpsi dan $\mathrm{Ce}$ adalah konsentrasi setelah teradsorpsi.

\section{HASIL DAN DISKUSI}

\subsection{Preparasi Adsorben Sabut Kelapa}

Sabut kelapa yang akan dijadikan adsorben metilen biru diperoleh dari pedagang kaki lima yang ada di Kota Kupang. Tahapan pengambilan sabut kelapa dilalui dengan melakukan observasi di lokasi pembuangan limbah sabut kelapa kemudian dilakukan sampling. Sabut kelapa yang diambil 
kemudian dibersihkan dan dipisahkan seratnya dari kulit buah kelapanya.
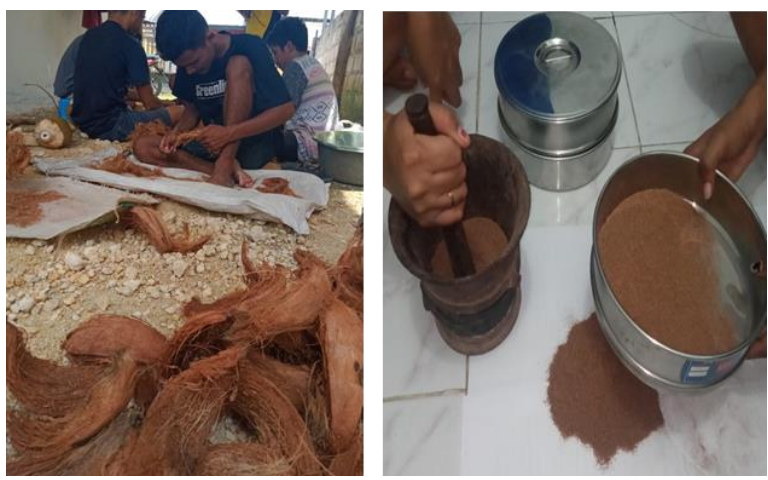

Gambar 1. Preparasi Adsorben

Sabut kelapa kemudian dihaluskan dengan ditumbuk hingga menghasilkan ukuran partikel yang kecil. Serbuk sabut kelapa kemudian diayak menggunakan ayakan berukuran 80 mesh seperti yang disajikan pada Gambar 1. Hasil ayakan yang diperoleh kemudian disebut sebagai adsorben sabut kelapa. Adsorben yang telah dihasilkan kemudian dicuci menggunakan aquades hingga bersih untuk menghilangkan material pengotor yang kemungkinan besar berada pada adsorben karena sabut kelapa tersebut diambil dari tempat pembuangan sampah.

\subsection{Penentuan Panjang Gelombang Serapan} Maksimum

Larutan stok yang dibuat adalah larutan MB 100 ppm. Larutan MB berkonsentrasi 100 mg/L kemudian diencerkan menjadi larutan MB 5 ppm. Sebanyak $10 \mathrm{~mL}$ larutan MB 5 ppm dan diukur absorbansinya pada panjang gelombang 400-800 nm. Data yang diperoleh menunjukkan bahwa serapan maksimum berada pada panjang gelombang $(\lambda) 665 \mathrm{~nm}$.

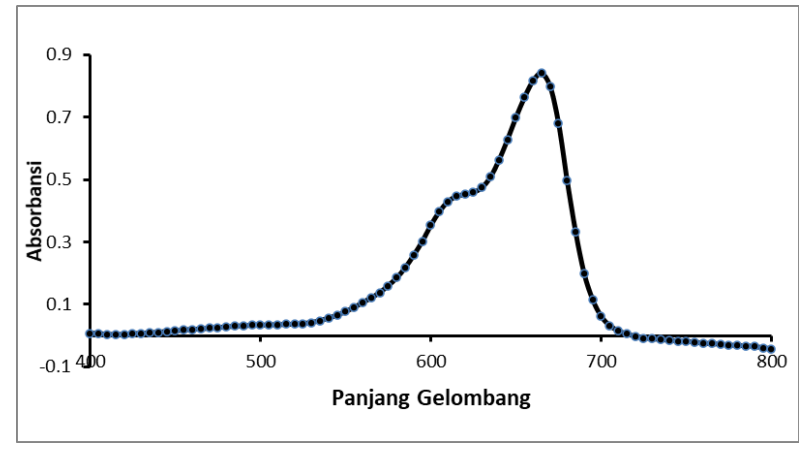

Gambar 2. Kurva Serapan Maksimum

Panjang gelombang serapan maksimum yang diperoleh pada penelitian ini yang ditampilkan pada Gambar 2 sama dengan hasil penelitian yang dilakukan oleh Huda dan Yulitanigtyas tentang Kajian Adsorpsi Methylene Blue Menggunakan Selulosa dari Alang-Alang [11].

\subsection{Pengaruh pH Terhadap Adsorpsi Metilen Biru \\ Berdasarkan data hasil pengukuran} panjang gelombang maksimum maka $665 \mathrm{~nm}$ digunakan sebagai panjang gelombang yang akan digunakan untuk adsorpsi metilen biru oleh adsorben sabut kelapa. Sabut kelapa yang digunakan untuk adsorpsi metilen biru sebanyak 0,1 gram. Adsorben sabut kelapa yang digunakan 0,1 gram ditempatkan pada wadah yang akan diisi oleh $20 \mathrm{~mL}$ larutan $\mathrm{MB}$ $10 \mathrm{mg} / \mathrm{L}$ kemudian pada wadah-wadah yang telah tersedia tersebut diatur pHnya dari 1 hingga 11. Data hasil penelitian menunjukkan bahwa adsorpsi maksimum terjadi pada $\mathrm{pH} 7$. 


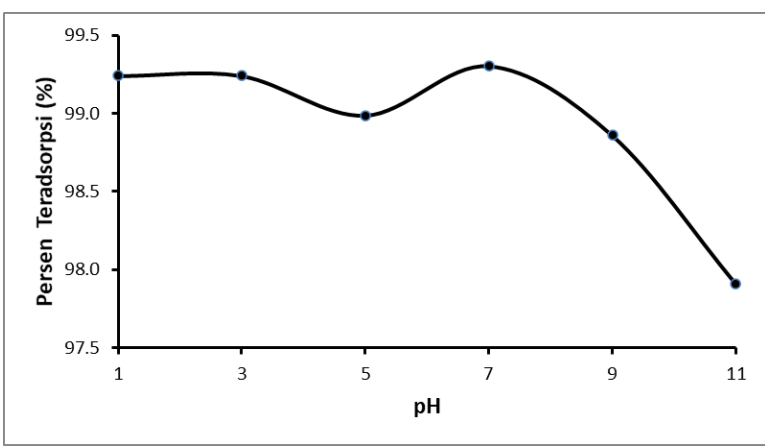

Gambar 3. Kurva pH versus persen absorbat yang teradsorpsi

Data yang ditampilkan pada Gambar 3 nampak sekilas bahwa pada $\mathrm{pH}$ rendah, adsorpsi metilen biru oleh adsorben sabut kelapa mencapai kesetimbangan dan akan mengalami penurunan pada $\mathrm{pH} 5$ kemudian kembali meningkat pada $\mathrm{pH}$ 7. Jika dicermati maka data persen adsorpsi $\mathrm{pH} 3$ sama dengan $\mathrm{pH} 7$, namun $\mathrm{pH}$ optimal yang digunakan adalah $\mathrm{pH}$ 7. Alasan pemilihan $\mathrm{pH} 7$ karena kondisi lingkungan selalu berada pada kisaran pH 6-8 dan jarang ditemukan lingkungan dengan kondisi $\mathrm{pH}$ 3. Pada $\mathrm{pH}$ yang sangat asam, metilen biru akan terprotonasi oleh ion $\mathrm{H}^{+}$sehingga akan menyebabkan perubahan struktur senyawa pada meliten biru menjadi kurang berwarna. Pada kondisi tersebut, ion $\mathrm{H}^{+}$akan berinteraksi dengan ion $\mathrm{Cl}^{-}$pada metilen biru yang dapat dilihat pada Gambar 4 sehingga atom $\mathrm{N}$ akan membentuk parsial positif dan akan mempermudah interaksi dengan gugus aktif yang bersifat hidrofilik (lignin, selullosa dan hemiselullosa) yang berada pada sabut kelapa. Namun karena pada $\mathrm{pH}$ rendah terdapat banyak ion $\mathrm{H}^{+}$dalam larutan, maka akan ada interaksi antara ion $\mathrm{H}^{+}$ tersebut dengan gugus hidrofilik pada adsorben yang mengakibatkan penghambatan terhadap interaksi adsorben dan adsorbat. Konsekuensi lainnya yaitu adsorpsi yang terjadi mencapai kesetimbangan pada kondisi asam sehingga tidak ada perubahan yang berarti pada nilai persen adsorpsinya. Sedangkan apabila dalam suasana basa, metilen biru akan berinteraksi dengan ion $\mathrm{Na}^{+}$ dari basa untuk membentuk garam, diikuti oleh penutupan parsial positif Nitrogen $(\mathrm{N})$ oleh ion $\mathrm{OH}^{-}$dari senyawa basa. Hal ini diperkuat oleh data penelitian yang dilakukan Kondo dan Arsyad [24], bahwa perlakuan alkali mampu menurunkan kandungan hemiselulosa, selulosa dan lignin sehingga interaksi antara adsorben dan adsorbat akan berkurang dan berakibat pada menurunnya persentase adsorpsi MB.

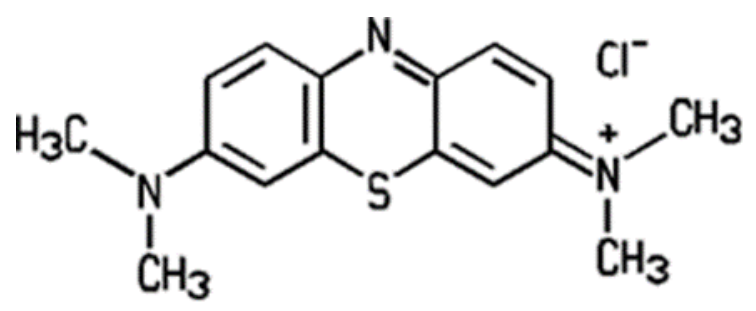

Gambar 4. Struktur Kimia Senyawa Metilen Biru

\subsection{Variasi Waktu Kontak}

Pengaruh waktu kontak terhadap adsorpsi metilen biru diukur dengan melakukan variasi waktu adsorpsi terhadap persen kapasitas adsorpsi metilen biru oleh adsorben sabut kelapa. 


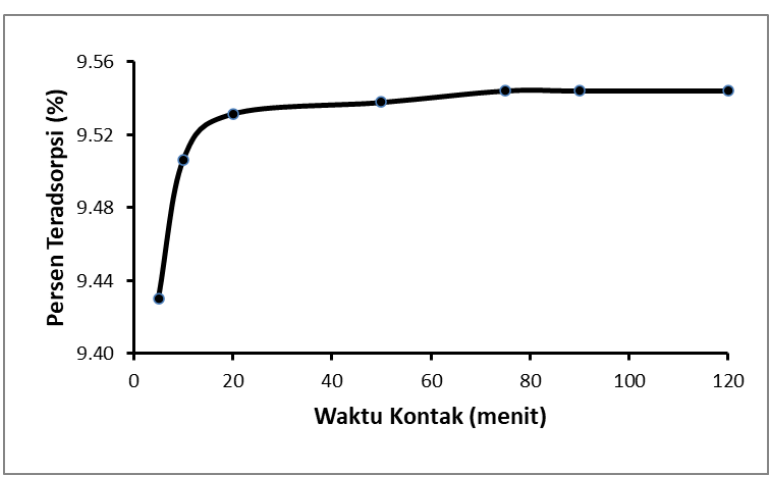

Gambar 5. Pengaruh Waktu Kontak Terhadap Persen Adsorpsi Metilen Biru

Berdasarkan data hasil analisis nilai adsorpsi, nampak pada Gambar 5 kesetimbangan adsorpsi mulai terlihat sejak waktu adsorpsi 20 menit, namun adsorpsi terhadap adsorbat masih terus berlangsung hingga waktu adsorpsi 75 menit baru diperoleh waktu kesetimbangan adsorpsinya. Ketika waktu adsorpsi berlanjut hingga 120 menit, tidak terdapat peningkatan ataupun penurunan persentase adsorpsi.

\subsection{Kinetika Adsorpsi Metilen Biru}

Parameter yang digunakan untuk menentukan kinetika adsorpsi metilen biru adalah variasi waktu kontak atau waktu adsorpsi. Model kinetika yang dapat ditentukan adalah kinetika orde nol, orde satu, orde dua, pseudo orde satu dan pseudo orde dua. Hasil kinetika reaksi metilen biru terdapat pada data Tabel 1.

Tabel 1. Model Kinetika adsorpsi metilen biru oleh adsorben sabut kelapa

\begin{tabular}{cccc}
\hline Model Kinetika & Satuan & $\begin{array}{c}\text { Konstanta } \\
\text { laju }\end{array}$ & $\mathrm{R}^{2}$ \\
\hline Orde Nol & Mol L $^{-1}$ Menit $^{-1}$ & 0,119 & -243 \\
\hline
\end{tabular}

\begin{tabular}{cccc}
\hline Orde Satu & Menit $^{-1}$ & $7 \times 10^{-5}$ & 0,470 \\
Orde Dua & $\mathrm{L} \mathrm{Mol}^{-1} \mathrm{Menit}^{-1}$ & $7 \times 10^{-6}$ & 0,469 \\
Pseudo Orde & $\mathrm{Menit}^{-1}$ & 0,002 & 0,553 \\
Satu & Gram mg $^{-1}$ menit $^{-}$ & 0,01 & 1 \\
Pseudo Orde & 1 & & \\
Dua & & & \\
\hline
\end{tabular}

Kinetika reaksi pseudo orde satu dapat dijelaskan menggunakan Persamaan 2 hingga Persamaan 6. Model kinetika ini menjelaskan batas kemampuan adsorbat teradsorpsi oleh adsorben yang mengontrol tercapainya waktu kesetimbangan, atau laju adsorpsi metilen biru sebanding dengan kesetimbangan MB yang terserap pada berbagai waktu kontak (qt-qe) yang dijelaskan pada Persamaan 2.

$$
\frac{d q t}{q t}=k_{1}(q e-q t)
$$

dengan qe adalah konsentrasi adsorbat pada kesetimbangan, qt adalah konsentrasi pada waktu t, k1 adalah konstanta laju adsorpsi dan $\mathrm{t}$ adalah waktu adsorpsi (menit). Pada saat $\mathrm{t}=$ 0 maka qt $=0$ dan pada saat $\mathrm{t}=\mathrm{t}$ maka $\mathrm{qt}=\mathrm{qt}$. Persamaan 2 dapat diekspresikan dalam bentuk integral menjadi bentuk lainnya yaitu Persamaan 3.

$$
\ln (q e-q t)=\ln q e-\ln k_{1} t
$$

Persamaan 3 biasanya disebut Lagergren orde satu atau pseudo orde satu. Nilai k1 diperoleh dengan membuat grafik hubungan $\ln (q e-q t) v s t$ yang ditunjukkan pada Gambar 6. Kinetika adsopsi orde satu 
tergantung pada jumlah adsorbat pada permukaan adsorben pada waktu tertentu dan pada waktu kesetimbangan.

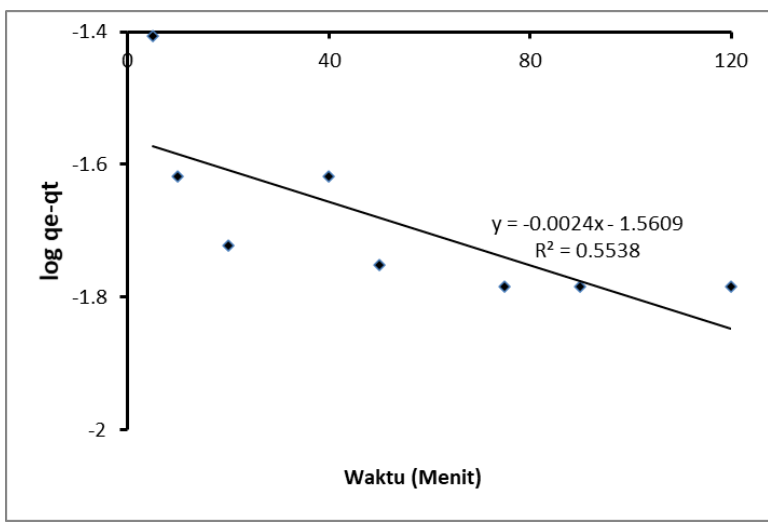

Gambar 6. Kurva Kinetika reaksi pseudo orde 1

Kinetka adsorpsi pseudo orde dua disebut juga sebagai reaksi kimia-semu yang dijabarkan pada Persamaan 4.

$$
\frac{d q t}{q t}=k_{2}(q e-q t)^{2}
$$

Jika diintegralkan dengan $\mathrm{t}=0$ hingga $\mathrm{t}=\mathrm{t}$ dan $\mathrm{q}=0$ dan $\mathrm{q}=\mathrm{qe}$, akan menghasilkan Persamaan 5 , dan jika diekspresikan dalam bentuk linier menjadi Persamaan 6.

$$
\begin{aligned}
& \frac{1}{q e-q t}=\frac{1}{q e}+k_{2} t \\
& \frac{t}{q t}=\frac{1}{k_{2} q e^{2}}+\frac{1}{q e} t
\end{aligned}
$$

Model kinetika reaksi pseudo orde 1 pada Gambar 6 menghasilkan nilai $R^{2}$ sebesar 0,553 sedangkan nilai linearitas yang diperoleh dengan menggunakan model pseudo orde 2 (Gambar 7) memiliki nilai $\mathrm{R}^{2}$ sebesar 1.

DOI: http://dx.doi.org/10.12962/j25493736.v5i2.7791

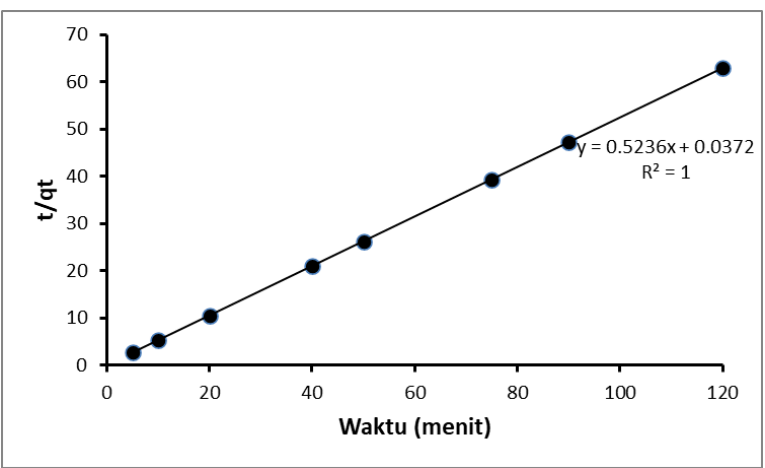

Gambar 7. Kinetika Reaksi Pseudo Orde 2

Data yang terdapat pada Gambar 7 menunjukkan bahwa adsorpsi metilen biru menggunakan adsorben sabut kelapa lebih cenderung mengikuti model kinetika reaksi pseudo orde dua. Dapat dijelaskan pula bahwa terdapat hubungan yang erat antara variabel t/qt dengan waktu, yaitu semakin besar waktu kontak antara adsorben dan adsorbat maka akan semakin besar pula nilai t/qt. Data yang terdapat pada Tabel 1 menunjukkan bahwa konstanta laju adsorpsi metilen biru adalah 0,01 gram $\mathrm{mg}^{-1}$ menit $^{-1}$, artinya bahwa dalam satu menit dengan menggunakan $1 \mathrm{mg}$ adsorben maka dapat diasorpsi sebesar 0,01 gram adsorbat. Semakin tinggi konstanta laju adsorpsi maka akan semakin cepat kemampuan adsorben untuk mengadsorpsi adsorbat.

\section{KESIMPULAN}

Adsorpsi terhadap metilen biru dapat dilakukan dengan menggunakan adsorben sabut kelapa. Berdasarkan hasil uji, adsorpsi metilen biru secara optimum terjadi pada $\mathrm{pH} 7$ dengan waktu kontak tercapainya 
kesetimbangan pada 75 menit dengan persentase adsorpsi sebesar 99,14\%. Kinetika adsorpsi reaksi yang dianalisis menunjukkan bahwa adsorpsi metilen biru yang terjadi sesuai dengan model kinetika pseudo orde dua dengan konstanta laju reaksi 0,01 gram mg${ }^{1}$ menit $^{-1}$.

\section{Ucapan Terima Kasih}

Penulis mengucapkan terimakasih kepada Kementerian Riset Teknologi dan Perguruan Tinggi yang telah memberi dana hibah PDP No. 8/E1/KPT/2020.

\section{DAFTAR PUSTAKA}

[1] D. Pathania, S. Sharma, and P. Singh, "Removal of methylene blue by adsorption onto activated carbon developed from Ficus carica bast," Arab. J. Chem., vol. 10, pp. S1445S1451, 2017.

[2] J. J. Salazar-Rabago, R. Leyva-Ramos, J. Rivera-Utrilla, R. Ocampo-Perez, and F. J. Cerino-Cordova, "Biosorption mechanism of Methylene Blue from aqueous solution onto White Pine (Pinus durangensis) sawdust: Effect of operating conditions," Sustain. Environ. Res., vol. 27, no. 1, pp. 32-40, Jan. 2017.

[3] S. Hashemian, M. K. Ardakani, and H. Salehifar, "Kinetics and Thermodynamics of Adsorption Methylene Blue onto Tea Waste $/ \mathrm{CuFe}_{2} \mathrm{O}_{4}$ Composite," Am. J. Anal. Chem., 2013.

[4] Riyanto, "Pengolahan Limbah Zat Warna Industri Batik Dengan Metode Elektrolisis Menggunakan Elektroda Komposit Karbon (C-PVC)", Posiding Seminar Nasional Penelitian, Pendidikan dan Penerapan MIPA
Fakultas MIPA, Universitas Negeri Yogyakarta, 2013, pp 107-113

[5] R. Zuo et al., "Photocatalytic degradation of methylene blue using TiO2 impregnated diatomite," $A d v$. Mater. Sci. Eng., vol. 2014, 2014.

[6] Hardeli, A. Ramadhani, D. Kurniawati, N. Andriko, and H. Sanjaya, "Degradasi Methyl Violet Dan Methylen Blue Oleh Fotokatalis $\mathrm{TIO}_{2}$ ", Jurnal EKSAKTA, Vol. 1, Tahun XV, 2014.

[7] E. G. Fransina and M. F. J. D. P. Tanasale, "Studi Kinetika Adsorpsi Biru Metilena pada Kitin dan Kitosan," J. Sains MIPA, vol. 13, no. 3, pp. 171176, 2008.

[8] L. Badriyah and M. P. Putri, "Kinetika Adsorpsi Cangkang Telur pada Zat Warna Metilen Blue," Alchemy, vol. 5, no. 3, p. $85,2018$.

[9] B. H. Hameed, "Spent tea leaves : A new non-conventional and low-cost adsorbent for removal of basic dye from aqueous solutions," vol. 161, pp. 753-759, 2009.

[10] D. Fitriani, D. Oktiarni, and Lusiana, "Pemanfaatan Kulit Pisang Sebagai Adsorben Zat Warna Methylene Blue," J. Gradien, vol. 11, no. 2, pp. 10911095, 2015.

[11] T. Huda and T. K. Yulitaningtyas, "Kajian Adsorpsi Methylene Blue Menggunakan Selulosa dari AlangAlang," IJCA (Indonesian J. Chem. Anal., vol. 1, no. 01, pp. 9-19, 2018.

[12] S. J. Kulkarni, R. W. Tapre, S. V. Patil, and M. B. Sawarkar, "Adsorption of phenol from wastewater in fluidized bed using coconut shell activated carbon," Procedia Eng., vol. 51, no. NUiCONE 2012, pp. 300-307, 2013.

[13] O. Priyanka, R. Sudesh, and S. Kunwar, "Modified coconut fiber used as adsorbent for the removal of 2chlorophenol and 2,4 ,6trichlorophenol from aqueous solution," South African J. Chem. Eng., vol. 19, no. 1, pp. 1-21, 2014. 
[14] S. Rangabhashiyam, N. Anu, and N. Selvaraju, "Sequestration of dye from textile industry wastewater using agricultural waste products as adsorbents," J. Environ. Chem. Eng., vol. 1, no. 4, pp. 629-641, 2013.

[15] K. A. Adegoke and O. S. Bello, "Dye sequestration using agricultural wastes as adsorbents," Water Resour. Ind., vol. 12, pp. 8-24, 2015.

[16] M. E. Ferama Sari, S. Suprapto, and D. Prasetyoko, "Adsorpsi Pb2+ menggunakan Sodalit dari Kaolin Bangka Belitung," Akta Kim. Indones., vol. 5, no. 1, p. 1, 2020.

[17] Z. V. Nugraheni, W. P. Utomo, Q. A'yuni, N. A. Agustina, J. Kholik, and C. Puspita, "Penggunaan Pektin Kulit Jeruk Manis (Citrus sinesis) sebagai Absorben untuk Mengurangi Kadar Ion Kromium (VI) pada Sampel Air Sungai Jagir," Akta Kim. Indones., vol. 3, no. 1, p. 112, 2018.

[18] H. K. Hansen, F. Arancibia, and C. Gutiérrez, "Adsorption of copper onto agriculture waste materials," J. Hazard. Mater., vol. 180, no. 1-3, pp. 442-448, 2010.

[19] P. Muensri, T. Kunanopparat, P. Menut, and S. Siriwattanayotin, "Effect of lignin removal on the properties of coconut coir fiber/wheat gluten biocomposite," Compos. Part A Appl. Sci. Manuf., 2011.

[20] A. Abdullah, S. B. Jamaludin, M. Mohd Noor, and K. Hussin, "Composite cement reinforced coconut fiber: Physical and mechanical properties and fracture behavior," Aust. J. Basic Appl. Sci., 2011.

[21] P. Lertwattanaruk and A. Suntijitto, "Properties of natural fiber cement materials containing coconut coir and oil palm fibers for residential building applications," Constr. Build. Mater., 2015.

[22] N. K. Mondal, R. Bhaumik, and J. K. Datta, "Removal of fluoride by aluminum impregnated coconut fiber from synthetic fluoride solution and natural water," Alexandria Eng. J., vol. 54, no. 4, pp. 1273-1284, 2015.

[23] A. Kamari, S. N. M. Yusoff, F. Abdullah, and W. P. Putra, "Biosorptive removal of $\mathrm{Cu}(\mathrm{II}), \mathrm{Ni}(\mathrm{II})$ and $\mathrm{Pb}(\mathrm{II})$ ions from aqueous solutions using coconut dregs residue: Adsorption and characterisation studies," J. Environ. Chem. Eng., vol. 2, no. 4, pp. 1912-1919, Dec. 2014.

[24] Y. Kondo and M. Arsyad, "Analisis Kandungan Lignin, Sellulosa, dan Hemisellulosa Serat Sabut Kelapa Akibat Perlakuan Alkali," INTEK J. Penelit., vol. 5, no. 2, p. 94, 2018. 